\title{
Transformational Leadership Styles Pre- and Post-Trauma
}

\author{
Charles A. Kramer \\ Vincennes University \\ Stuart A. Allen \\ Robert Morris University
}

\begin{abstract}
Previous literature suggests that exposure to trauma has both positive and negative impacts on leadership and leadership development, although there is a lack of empirical research. This exploratory study compared military leaders' use of transformational leadership styles (TLS) before and after trauma exposure from the followers' perspective. This study used a retrospective pretest design to survey veteran and active duty military personnel. Significant differences were found between pre- and post-trauma exposure TLS ratings, with a mean decline in the TLS after trauma exposure. The analysis of the open-ended questions indicated a reduction in the use of the TLS after trauma, but identified positive changes in some cases. There was no evidence that changes in the TLS were concentrated in any of the five styles.
\end{abstract}

\section{Introduction}

Military leaders who are experiencing posttraumatic stress symptoms (PTSS) or posttraumatic stress disorder (PTSD) after exposure to trauma may encounter changes in their leadership style as a result of decreased emotional (Card-Mina, 2011; George, 2000, Ingram, \& Cangemi, 2012; Zineldin \& Hytter, 2012) and cognitive functioning (e.g., Burriss, Ayers, Ginsberg, \& Powell, 2008). The inner theater of a leader's mind is expressed in his or her leadership (Kets De Vries, 2006) and, therefore, inner turmoil resulting from PTSS or PTSD has the potential to impact followers' impressions of the leader through behavioral changes after trauma exposure. However, negative long-term outcomes from exposure to trauma occur for relatively few soldiers and such exposure can be a positive crucible and source of meaning and growth for leaders (Matthews, 2014; Wolf Williams \& Allen, 2014).

There is limited research on the impact of PTSD on leadership (Schneider, 2012), especially changes in leadership style associated with trauma exposure. Bennis and Thomas (2007) specifically discuss the impact of military experience and other adverse events and hardships on leadership development. Similarly, multiple scholars point to both positive and negative leadership development outcomes from adversity (Dotlich, Noel, \& Walker, 2004; McCall, Lombardo, \& Morrison, 1988; Thomas, 2008; Yip \& Wilson, 2010). Despite these authors identifying this connection, no empirical studies were located.

Positive outcomes of trauma are highlighted in the literature on posttraumatic growth (Card-Mina, 2011; Tedeschi \& Calhoun, 2004), which also apply to trauma during military service (Bennis \& Thomas, 2007). Leaders may develop skills, knowledge, and attitudes that strengthen their leadership through these harrowing experiences. For example, Wolf Williams 
and Allen (2015) report that trauma was a precipitating event in some cases of pro-social (nonprofit) leaders' emergence. They found that trauma survivors often founded nonprofit organizations or movements related to causes associated with their experiences of trauma, thereby creating positive outcomes from their own adverse experiences.

This exploratory study attempted to address the gap in empirical research on how leadership styles change after trauma, relying on the observations of followers within a military context. There are few professional contexts outside of law enforcement and first responders (e.g., firefighters) where leaders and followers are as frequently exposed to traumatic events, providing a suitable population through which to investigate this phenomena. Although this study focused on a military context, trauma exposure also occurs in other contexts and understanding changes in leaders' styles after trauma has implications for leaders outside of the military.

\section{Purpose of the Study}

The purpose of this study was to examine the relationship between trauma exposure and changes in Bass's (1985) transformational leadership styles (TLS) from the perspective of veterans and active duty military service members who have observed their leaders before and after exposure to a potentially traumatizing event during military service. As discussed in the literature review below, Bass's theory of transformational leadership and the TLS are well accepted approaches to conceptualizing and measuring leadership applied in military and nonmilitary contexts. The specific objectives of the study were to: a) identify if followers perceived changes in the TLS of their military leaders after these leaders were exposed to potentially traumatizing events; b) identify the direction and strength of changes in overall transformational leadership and the individual TLS after trauma exposure; and c) identify themes to the followers' descriptions of positive and negative changes to the leaders' leadership after trauma exposure.

\section{Post-traumatic Stress and Leadership}

PTSS or PTSD can result from exposure to traumatic events in the military (e.g., combatrelated death). PTSD occurs after a person experiences or witnesses a life threatening event and results in symptoms such as intrusive thoughts or memories, avoiding trauma-related stimuli, negative alterations in cognitions and mood, and changes in arousal and reactivity (American Psychiatric Association [APA], 2013). PTSD is a mental health diagnosis typically determined six months after a traumatic event (APA, 2013). PTSS is not a diagnosis and refers only to PTSD-like symptoms, which may be transient while a person recovers from trauma exposure or may be indicative of PTSD onset (Howell, 2006).

Posttraumatic growth is defined as "positive psychological change experienced as a result of the struggle with highly challenging life circumstances" (Tedeschi \& Calhoun, 2004, p. 1) and is seen in five domains: "greater appreciation of life and changed sense of priorities; warmer, more intimate relationships with others; a greater sense of personal strength; recognition of new possibilities or paths for one's life; and spiritual development" (p. 6). While the leadership literature acknowledges traumatic and adverse events as sources of learning and growth (Bennis \& Thomas, 2007; Moxley \& Pulley, 2004; Thomas, 2008), it also acknowledges that some 
leaders "emerge confused and demoralized" (Thomas, 2008, p. 101) or lose their ability to lead (Schneider, 2012). Such negative outcomes are unlikely for the majority of leaders or may be temporary during adjustment periods (Matthews, 2014). Yip and Wilson (2010) discuss:

Whether it involves a business mistake, job loss, demotion, lousy job, or personal trauma, adversity is a powerful crucible for leadership development ... Profound insights are gained not in the moment but after the passage of time. Adverse situations can teach resilience and integrity in the face of events beyond one's control, compassion for others, and a more balanced approach to life (p. 79).

It is important not to polarize trauma's effects on leadership as positive or negative, as many leaders remain effective despite experiencing PTSS or PTSD. For example, Wolf Williams and Allen (2015) discuss "the common co-occurrence of posttraumatic distress symptoms with effective [prosocial] leadership" (p. 97). In addition, recovery may occur with time.

Military unit leadership along with benefit-finding (seeing benefits in adverse events or circumstances) have been reported as buffers between combat exposure and PTSD symptoms (Wood, Foran, Britt, \& Wright, 2012). Trait resilience and resilience training have also been shown to moderate the impact of trauma on the long-term development of PTSD (Matthews, 2014). However, further exploration of focal changes in leadership styles may provide insight into changes that impact leadership effectiveness.

Schneider (2012) argues that "most studies on PTSD rarely deal with the condition among officers, largely because of a professional paradox and an institutional bias that do not admit its existence" (p. 76). Hence, military leaders may hide or ignore their own suffering, even when openness about these challenges may facilitate their recovery. Card-Mina (2011) and Schneider (2012) encourage leaders to be courageous in speaking about PTSD to reduce this stigma.

PTSD is thought to be more widespread in the general population than acknowledged (O'Connor, Lasgaard, Spindler, \& Elklit, 2007), highlighting the need to study leadership capacity while experiencing PTSS or PTSD in military and non-military populations. Similar to in extremis leadership, or leadership in extreme situations (Fisher, Hutchings, \& Sarros, 2010; Kolditz, 2007), military trauma studies have implications for non-military leaders and organizations, even though the contexts differ. For example, research on PTSD and military leadership may apply to first responders (e.g., firefighters, police) and civilian trauma survivors of events (e.g., motor vehicle accidents, natural disasters, traumatic medical experiences, and crime) as the extreme nature of experiences raise similar existential questions and victims may follow a similar recovery process (Howell, 2006; Matthews, 2014). After traumatic events, military leaders may also remain in their deployment, be redeployed, or take leadership roles in public, for profit, and nonprofit organizations. This suggests that understanding the consequences and recovery from military trauma is of interest to the military itself, but also to those who work with and support military veterans after their service. Military veterans need ongoing support after their service - harnessing their leadership skills developed through military experience and education also benefits society (Kolditz, 2009; Matthews, 2014). 


\section{Transformational Leadership}

Transformational leadership is applied in various branches of the U.S. military (AFHANDBOOK, Department of the Air Force, 2015; FM-22-100, U.S. Army, 1999). The TLS are believed to have a transforming effect on followers and include five styles: idealized influence attributes (IIA), idealized influence behaviors (IIB), individualized consideration (IC), inspirational motivation (IM), and intellectual stimulation (IS) (Avolio, Bass, Walumbwa, \& Zhu, 2004). In Avolio and Bass's (1991) Full Range Leadership Model the TLS are contrasted with the transactional leadership styles, including contingent reward (CR) and management by exception (MBE), and the passive and ineffective laissez-faire (LF) style. Transformational leaders display attributes (IIA, e.g., values, a sense of purpose) and behaviors (IIB, e.g., ethical conduct) others want to emulate, resulting in followers' desire to be associated with and follow the leader. Follower ratings on the TLS have been shown to predict follower satisfaction and willingness to exert extra effort (Avolio et al., 2004; Tejeda, Scandura, \& Pillai, 2001).

IC describes the personalized attention given to followers as unique individuals in the form of coaching, listening, challenging assignments, and support. IM is present in leaders who provide a clear, articulated vision that inspires followers to have high expectations and embrace the organization's shared vision. Leaders displaying IS encourage followers to explore creative approaches to problems, contribute their ideas, and seek opportunities to learn (Avolio, \& Bass, 1991; Avolio, Bass, Walumbwa, \& Zhu, 2004; Bass, 1985; Judge \& Piccolo, 2004). The five TLS are strongly related to each other (Tejeda et al., 2001). In the present study the researchers focused on the five TLS and not the transactional styles as these are accepted to be the most effective styles.

Considering that military leaders' leadership styles depend on their physical, emotional, and cognitive wellbeing, it can be anticipated that PTSS may influence the expression of the TLS. Kets De Vries (2006) and Thompson (2010) both discuss the outcomes of emotions, mood, and cognitive hygiene on leadership. For example, "negative alterations in cognitions and mood" (Criterion D, DSM-V, APA, 2013) or hopelessness about the future (Jakupcak et al., 2011) associated with PTSD or PTSS could impact a leader's ability to engage in IM, where leaders express a clear and positive vision of the future. Previous studies also note the impact of PTSD on cognitive performance (e.g., Burriss, Ayers, Ginsberg, \& Powell, 2008). As one example, a leader having difficulty concentrating or remembering might be ineffective at IS, where a leader provides a different and stimulating perspective on problems.

The TLS are frequently measured with 360-degree instruments like Avolio et al.'s (2004) Multi-Factor Leadership Questionnaire (MLQ), providing evidence of a leader's expression of the TLS through the eyes of followers, peers, supervisors, and the leader themselves. In the case of leaders experiencing transient PTSS or long-term PTSD after traumatic events, it would be anticipated that the leader's capacity to apply the TLS might be decreased and noticeable to followers, peers, or supervisors. Unfortunately, if the leader and follower were both exposed to trauma, it may be a time that the follower most needs the TLS (Howell, 2006). Gunia, Sipos, LoPresti, and Adler (2015) state "Research has suggested that military leaders, like other leaders, can help to buffer their subordinates against physical, psychological, and organizational problems using an established set of general leadership skills" p. 198). In addition, stressful 
interactions with a direct supervisor greatly increased the likelihood of psychological distress for first responders (Boxer \& Wild, 1993). The TLS are a potential buffer and support for followers in military contexts. Allen and Ortlepp (2000) found work-based social support correlated negatively $(r=-.35, p<.00)$ with PTSS for security officers who experienced trauma in the line of duty.

Howell (2006) provides one of the few studies that has examined the relationship between the TLS and PTSD. His study surveyed a sample of 250 firefighters, measuring the TLS and PTSS, but found no significant relationship between followers' perceptions of the leaders' TLS and their PTSS self-ratings, as well as no mediating effect of the TLS between traumatic experience and PTSS. However, this may partially be explained by the firefighters' occupational resilience (resilience developed in training and on the job). Howell's study focused on the followers' own traumatic experience and PTSS, considering the TLS as moderators of PTSS, whereas the present study focused on trauma-exposed leaders and changes in their exhibition of the TLS from before to after trauma exposure.

\section{Methodology}

This exploratory study used a mixed methods quantitative survey to measure subordinates' perceptions of changes in their military leader's leadership styles from before to after trauma exposure. An ex post facto approach was used (Silva, 2010) as it was not possible for the researchers to control the independent variable (trauma exposure during military deployments). Ex post facto designs may be impacted by participants' accurate recall of events (Krathwohl, 2009). The retrospective pretest design applied in this study has been argued to have merit through its ability to study participants' perceptions of changes that occurred as result of events or interventions. Relative to a pre-test post-test design where the dependent variable is measured before and after an intervention or event, a retrospective pretest design relies on participants' memories of their thoughts or feelings before and after an event or intervention. Some critics have, however, taken the view that demand characteristics (expectations of what participants think the researcher is looking for) may influence results (Hannum \& Martineu, 2008; Pratt, McGuigan, \& Katzev, 2000), introducing a limitation when using this method. However, Hannum and Martineu argue that the method can produce valid results.

In the present study, researchers relied on followers' perceptions of changes in the observed leaders' TLS before and after the leader was exposed to trauma, without measuring specific evidence of PTSD or PTSS in the rated military leaders. There are a number of challenges to studying leaders with PTSD, including ethical issues related to privacy. Identifying active leaders currently experiencing PTSD or PTSS and having their followers rate their TLS would involve substantial ethical challenges and sample access limitations. Given these challenges, a retrospective pretest design is a practical approach to studying changes in leadership styles, reducing the ethical challenges as well as the uncontrollable nature of trauma as the independent variable.

Population and Sample. This study's population was U.S. military veterans and active duty service members who served under the command of leaders exposed to trauma in the line of duty. Jones et al. (2012) state that only $2.7 \%$ of deployed personnel, from a sample of 1,431 U.K. 
armed forces, were classified as probable PTSD cases. Matthews (2014) reports PTSD rates as high as $20 \%$ among U.S. veterans of the Iraq and Afghanistan wars, with lower rates among more highly trained or elite soldiers. PTSD is only diagnosed after symptoms have been present for a few months and during the first few months many soldiers will recover (Kessler, Sonnega, Bromet, Hughes, \& Nelson, 1995). As a result, this study faced a number of challenges in locating individuals who had observed a leader before and after trauma exposure. A purposive sampling approach (Gay, Mills, \& Airasian, 2011) was therefore applied.

Veteran service organizations (VSOs) and active duty commands (ADCs) were contacted to request access to returned service members, and five organizations agreed (3 VSOs, and 2 ADCs). After IRB approval, the organizations' leaders emailed an invitation to members or posted the invitation in a newsletter. Participants who responded to the requests were provided a link to the survey and could self-select to complete a survey after confirming: a) that their military unit was deployed to a combat-designated area and engaged in actual combat or direct combat support, or was exposed to other noncombat-related trauma in the line of duty (e.g., accidents); b) they knew and observed the leader of their unit for at least a few (2-3) months before and after that leader was exposed to trauma; and c) could recall that leader's leadership style before and after the trauma. The last criterion attempted to control for memory degradation. Participation was voluntary, and anonymity was assured to increase participation. Participants did not identify the observed leader.

Forty-five completed responses were received (26 active duty or recently deployed, 18 veterans, 1 undisclosed) exceeding Daniel's (2012) minimum recommended sample size (>20) for exploratory research. As a difficult-to-study phenomenon, the small sample was deemed acceptable by the researchers for an exploratory study.

Measures. The TLS subscales of the MLQ 5X-Short (Avolio et al., 2004) were used to measure leadership style. Participants rated their leader twice, thinking of their leader before and after trauma exposure. Each MLQ item was presented once with the rating scale repeated twice after asking participants to rank the leader before and after the trauma event. The twenty questions use a 5 point rating scale $(0$ - not at all, 1 - once in a while, 2 -sometimes, 3 -fairly often, 4 -frequently, if not always) with four items for the five TLS subscales. Total TLS and the five TLS subscale (IIA, IIB, IC, IM, IS) scores were calculated for the pre- and post-trauma ratings. Studies using the MLQ report acceptable internal reliability and validity, especially predictive validity (Den Hartog, Van Muijen, \& Koopman, 1997; Judge \& Piccolo, 2004; Tejeda et al., 2001).

Cronbach scale alphas for the total scale were .89 (pre) and .95 (post), both above the .70 standard typically required (Nunnally, 1967). Post trauma subscales were also above .70. Pretrauma subscales for IIA, IIB, and IS ranged between .62 and .68, while IC and IM were .52 and .54. As an exploratory study, the scale and subscale level scores are worthy of consideration, however, the low reliabilities on the IC and IM pre-trauma subscales suggest caution is required in the interpretation of results with those subscales.

Two other questions were included in the survey: a) a closed-ended question (yes or no) presented prior to the MLQ assessed if the participants observed global changes in leaders' 
leadership styles ("Did you see a change in your leader's style after the traumatic event?"); b) an open-ended question was presented after the MLQ exploring participants' perceptions of changes in their own words: "Considering your leader's leadership style prior to and after combat (traumatic) exposure, please describe what changes, if any, you observed." These questions provided an additional source of data by gaining participants' overall impressions of changes in their leader's style, prior to any influence that completing the MLQ might have on that impression, as well as allowing participants to describe observed changes in their own words.

Data Analysis. The data analysis relied upon a matched sample $t$ test (Howell, 2013) contrasting pre- and post- trauma ratings of the leaders on the five TLS. The data appear normal when checked visually using histograms (Bordens \& Abbott, 2002). A 2 x 5 repeated measures ANOVA (Howell, 2013) was used to determine if changes in the TLS after trauma exposure were significantly different between the five styles. Responses to the open-ended question were analyzed using a generic content analysis coding procedure (Bryman, 2012; Patton, 2015).

\section{Results}

A yes-no frequency was calculated for the single item question: "Did you see a change in your leader's style after the traumatic event?". Thirty-nine $(86.7 \%)$ participants replied yes, four $(8.9 \%)$ responded no, and two (4.4\%) did not respond. Means for the total TLS on the MLQ were compared for veteran and active duty subgroups pre-trauma (veterans $M=3.56, n=18$, active duty $M=3.51, n=26$ ) and post-trauma (veterans $M=2.60, n=18$, active duty $M=2.48$, $n=26)$. A t-test did not identify any significant differences $(p>.05)$ between these subgroups. Correlations between the pre- and post-trauma total TLS means were weak $(r=.18, p>.05)$. Only IIA pre- and post-trauma scores were correlated $(r=.31, p<.05)$. Harman's single factor test (Podsakoff, McKenzie, Lee, \& Podsakoff, 2003) was used as a general measure of common method variance. With $R^{2}=28.87$ (percentage of variance explained, $N=45$ ), common method variance is unlikely to be high.

A matched samples $t$-test and Cohen's $d$ (1988) were computed comparing the pre- and post-test means (see table 1) for the subscales and total MLQ scale. Significant differences $(p<$ $.00)$ were found for the total scale and all subscales, showing a mean reduction of 1.02 in the TLS subscale scores after trauma exposure describing a shift from the scale anchor "fairly often" to "sometimes". Judge and Bono (2004) report a similar use of a single score for transformational leadership noting "when only transformational leadership behaviors are considered, a single transformational leadership factor appears to represent the data well" (p. 902). Correlations between the pre- and post-trauma subscales and totals are displayed in table 1. Cohen's $d$ indicated large effects (Cohen, 1988) for total TLS and all subscales, except for IIA which revealed a medium effect. 
Table 1. Intercorrelations of Pre- and Post-Trauma TLS $(N=45)$

\begin{tabular}{lcccccccc}
\hline Measure & 1 & 2 & 3 & 4 & 5 & 6 & $M$ & $S D$ \\
\hline 1. IIA & $.31 *$ & $.84 * *$ & $.78 * *$ & $.81^{* *}$ & $.87 * *$ & $.94 * *$ & 2.60 & 1.11 \\
2. IIB & $.80^{* * *}$ & .26 & $.81^{* *}$ & $.86^{* *}$ & $.79 * *$ & $.94 * *$ & 2.62 & 1.02 \\
3. IM & $.74 * *$ & $.78^{* *}$ & .29 & $.82^{* *}$ & $.70^{* *}$ & $.89 * *$ & 2.42 & .93 \\
4. IS & $.68^{* *}$ & $.75^{* *}$ & $.68^{* *}$ & $.02^{*}$ & $.77 * *$ & $.92 * *$ & 2.61 & .89 \\
5. IC & $.73^{* *}$ & $.62 * *$ & $.63^{* *}$ & $.55^{* *}$ & .17 & $.90^{* *}$ & 2.41 & .98 \\
6. Total & $.91 * *$ & $.91 * *$ & $.88^{* *}$ & $.84^{* *}$ & $.81 * *$ & .18 & 12.67 & 4.54 \\
M & 3.66 & 3.55 & 3.68 & 3.49 & 3.36 & 17.73 & & \\
SD & .77 & .77 & .70 & .71 & .68 & 3.17 & & \\
\hline
\end{tabular}

Note: Intercorrelations for pre-trauma TLS are presented below the diagonal, and intercorrelations for posttrauma TLS are presented above the diagonal. Means and standard deviations for pre-trauma TLS are presented in horizontal rows, and means and standard deviations for post-trauma TLS are presented in vertical columns. Intercorrelations between the same TLS pre- and post-trauma measures are displayed on the diagonal.

$* p<.05 * * p<.001$

A 2 x 5 repeated measures (within-groups) ANOVA (Observation Period [pre-trauma, post-trauma] x TLS [IIA, IIB, IM, IS, IC]) identified that there was no main effect of the five styles on the TLS scores $(F(1,440)=1.01, p>.05)$, suggesting no differences between subscale scores as a function of observation period. There was a significant main effect of observation period on the TLS scores $(F(1,440)=152.48, p>.00)$, supporting the finding that overall pretrauma TLS scores were significantly higher than post-trauma TLS scores (see Table 1 for $M$ and $S D)$. There was no significant interaction between the two factors $(F(1,440)=.686)$. A count of the percentage of positive or negative changes in the total TLS scores indicated that $10(22.2 \%)$ participants observed a positive or no change in the total TLS. Positive or no change was observed in the TLS subscales: IS (31.1\%), IIA (22.2\%), IIB (26.7\%), IM (13.3\%), and IC $(28.9 \%)$.

Table 2. Contrast of Pre-Trauma and Post-Trauma TLS $(N=45)$

\begin{tabular}{|c|c|c|c|c|c|c|c|c|c|}
\hline \multirow{2}{*}{ Variable } & \multicolumn{4}{|c|}{$\begin{array}{c}\text { Post- } \\
\text { Trauma }\end{array}$} & \multirow[b]{2}{*}{$t$} & \multirow[b]{2}{*}{$p$} & \multicolumn{2}{|c|}{$95 \% \mathrm{CI}$} & \multirow[t]{2}{*}{$\begin{array}{c}\text { Cohen's } \\
\text { d }\end{array}$} \\
\hline & $M$ & $S D$ & $M$ & $S D$ & & & $L L$ & $U L$ & \\
\hline Overall MLQ & 3.55 & .63 & 2.53 & .91 & 6.72 & .00 & .71 & 1.32 & 1.30 \\
\hline $\begin{array}{l}\text { Intellectual } \\
\text { stimulation }\end{array}$ & 3.49 & .72 & 2.61 & .89 & 5.17 & .00 & .53 & 1.21 & 1.09 \\
\hline $\begin{array}{l}\text { Idealized influence - } \\
\text { attributes }\end{array}$ & 3.66 & 1.77 & 2.60 & 1.11 & 6.19 & .00 & .71 & 1.39 & 0.72 \\
\hline $\begin{array}{l}\text { Idealized influence - } \\
\text { behavior }\end{array}$ & 3.55 & .77 & 2.62 & 1.02 & 5.63 & .00 & .60 & 1.26 & 1.03 \\
\hline $\begin{array}{l}\text { Inspirational } \\
\text { motivation }\end{array}$ & 3.68 & .70 & 2.42 & .93 & 8.55 & .00 & .96 & 1.56 & 1.53 \\
\hline $\begin{array}{l}\text { Individualized } \\
\text { consideration }\end{array}$ & 3.36 & .68 & 2.41 & .98 & 5.81 & .00 & .62 & 1.28 & 1.13 \\
\hline
\end{tabular}

Note: $\mathrm{CI}$ - confidence interval; $\mathrm{LL}=$ lower limit; $\mathrm{UL}=$ upper limit 
The responses $(N=33)$ to the single qualitative question inquiring about the nature of changes in the leader after trauma were coded. An initial coding was completed by one researcher, after which another experienced researcher, not part of study, reviewed the data and coding, resulting in $94 \%$ agreement. Two participants $(6.1 \%)$ provided statements indicating no changes in the rated leader's styles (e.g., "... is difficult to see changes"). Two participants (6.1\%) noted changes, but their statements could not be categorized as positive or negative ("I do not remember specific changes, but I know there were a few and others noticed as well'"). Twenty-six (78.8\%) described negative changes. Six (18.2\%) listed positive changes. Three participants $(9.1 \%)$ included both positive and negative examples of changes.

The examples of changes described by participants were categorized according to the TLS subscale they fit the best, but some applied to multiple subscales or overall TLS. Positive changes included greater interest in followers (IC), increased "team building toward a common goal" (IM), greater work ethic (IIB), recognition of others (transactional leadership, contingent reward), and treating life more preciously (IA). Negative changes included loss of flexibility with regimented or obsessive behavior (increased MBE), failure to consider alternative points of view (IS), failure to give credit to others (reduced CR and IIB), "small things became big things" (MBE), lost enthusiasm, emotion, humor, or energy (IM, IIA), lost concern for followers or people in general (IC, IIB, increased LF), becoming reclusive, preoccupied, withdrawn, or quiet (IM, IIA, LF), lost confidence (IIA), cold-heartedness, fault-finding, or angry behavior (IIA, IC), autocratic behavior (MBE), less care for appearance (IIA), slower thinking (IS), and inconsistent expectations (IM).

\section{Discussion}

The relationship between trauma exposure and changes in the TLS has not been explicitly addressed in empirical leadership and PTSD research. In this study followers' perceptions of their leader pre- and post-trauma were analyzed to identify the direction and extent of change, and to identify if changes were focused in any of the five TLS. While there was a significant difference between the overall pre- and post-trauma TLS ratings, the style means decreased uniformly, suggesting that trauma did not have a unique effect on any particular TLS. The main effect of trauma exposure highlights a broad reduction in the TLS, with large effects in all subscales, except IIA where a moderate effect size was observed. This may be because IIA includes evaluations of leaders' traits, which may include stable characteristics (e.g., personality, values) less impacted by trauma (Avolio \& Bass, 1991). For example, one participant described his leader as stern and suggested he could not discern changes in this trait after the trauma exposure.

The single yes-no question presented prior to the MLQ found the majority (86.7\%) of participants perceived changes in their leaders' styles, but this question did not inquire about the change's direction, which the MLQ results then clarified as predominantly in a negative direction. Overall, $77.8 \%$ of participants reported a negative change in the total TLS score. IM scores showed the highest level of change indicating that $86.7 \%$ of participants observed a reduced ability to inspire and motivate followers. Previous literature has noted that hopelessness about the future (Jakupcak et al., 2011) is one of the outcomes of PTSS and PTSD, which might directly impact the leader's ability to generate hope about the future through IM. Peterson, 
Walumbwa, Byron, and Myrowitz (2009) directly link transformational leadership and hope, noting positive impacts on organizational performance. Reduced IM would therefore appear to be a likely outcome during posttraumatic recovery or PTSD.

Consistent with previous literature on leadership development and adversity (Dotlich et al., 2004; McCall et al., 1988; Thomas, 2008; Yip \& Wilson, 2010) this study found evidence of both positive and negative leadership changes after trauma. The qualitative results supported the MLQ results showing that $78.8 \%$ noticed negative changes in their leaders' TLS, while $18.2 \%$ noted positive changes. These changes were consistent with the outcomes of posttraumatic growth discussed by Tedeschi and Calhoun (2004). Given that recovery from trauma may take time before the event is mastered and posttraumatic growth realized, the low percentage of positive changes observed might be explained by the length of the observation period: at least two to three months after the trauma. If participants had observed their leader for 1-2 years, they may have observed different outcomes. The analysis of the qualitative data did not highlight any distinct patterns in the changes to the five TLS and showed that changes were possible across the five styles.

Many participants observed positive changes in the TLS scores and written comments, highlighting that negative changes are not the only outcome following trauma exposure. For example, "This leader became much more interested in my welfare, direction, and personal satisfaction" is a description highly consistent with IC as an expression of transformational leadership (Avolio \& Bass, 1991). In addition, this agrees with Tedeschi and Calhoun's (2004) categorization of posttraumatic growth changes such as concern for others and changed priorities. Evidence of post-traumtic growth was clearly evident in the first two of Tedeschi and Calhoun's five domains of posttraumatic growth "greater appreciation of life and changed sense of priorities; warmer, more intimate relationships with others", but were not evident in the latter three "a greater sense of personal strength; recognition of new possibilities or paths for one's life; and spiritual development" (p. 6). Detailed interviews might provide further insights on change in each domain to determine whether growth is more likely in some domains than others.

There was evidence of the state of demoralization Thomas (2008) and Schneider (2012) suggest that some leaders experience after adversity. For example, one participant stated, "Before, he was motivated, after [...] little to no motivation." There was also evidence of the "negative alterations in cognitions and mood" (Criterion D, DSM-V, APA, 2013) that occur after trauma exposure. For example "reduced affect", "angry outbursts", and "slower thinking" were descriptions participants applied to their leader after the trauma. Other descriptions of negative changes also suggest reduced ability to lead in a transformational way including evidence of depersonalization, reduced expectations, withdrawal, and lower concern for others, each of which are essentially the opposite of what would be expected from a transformational leader (Avolio \& Bass, 1991).

Transformational leadership theory (Avolio \& Bass, 1991) proposes that the use of the five transformational styles leads to improved follower and organizational performance. The reduced use of these styles, which was observed in many of the leaders in this study after trauma exposure, may result in reduced individual and unit effectiveness. However, the positive changes 
observed agree with what would be expected as a result of posttraumatic growth (Tedeschi \& Calhoun, 2004) and might result in improved use of transformational leadership.

\section{Limitations and Recommendations for Further Research}

This study is limited by the sample size and retrospective pretest design. Other limitations include threats to internal validity, such as history and maturation (Bryman, 2012), and the potential impact of demand characteristics (Hannum \& Martineu, 2008). In addition, the internal consistency of two pre-trauma subscales (IC, IM) was lower than expected. Giving consideration to the wording of the MLQ items and their suitability to a retrospective pretest design might enable future researchers to gather reliable data on changes on all five dimensions of the TLS.

It is not easy or practical to collect data before and after an uncontrollable event like trauma exposure. However, the arguments outlined by authors such as Hannum and Martineu (2008) suggest that data collected via retrospective pretest designs can be meaningful. While the researchers avoided creating demand characteristics in the surveying process, it is possible that participants focused on negative changes to the leaders' TLS through their awareness of the study's focus on PTSS and PTSD, along with stereotyped or false beliefs about PTSD's prevalence and effects. Despite these limitations, the qualitative data supported the quantitative results through participants' descriptions of changes in their own words, which did not suggest they were imposing assumptions about PTSD being the assumed cause (e.g., "my leaders change was so evident because my leader did not lead anymore. He seemed to not care anymore that our well-being is important").

The researchers purposefully sought followers who had observed a trauma-exposed leader, which is fairly uncommon, limiting the sample size. The time frame of observation was not controlled for; only a minimum observation period of 2-3 months before and after the trauma was required. Some of the observed negative changes in the TLS may have been part of the acute stress of deployment or resolved with time and ultimately contributed to leadership growth. Recovery and mastery of trauma can be a slow adaptive process (Matthews, 2014).

The length and nature of the observation period excludes the possibility of a PTSD diagnosis, precise knowledge of leaders' trauma exposure, or awareness of the stages of posttrauma reaction or recovery. Hence, the study's results may only provide insight on temporary changes evident at the time of observation. Many of the examples of leaders explored in Wolf Williams and Allen (2014) suggested an initial decline in functioning for a period of months or years after trauma exposure, followed by longer-term positive growth period. Onset of PTSD can be delayed by months and symptoms can abate within months or years (Kessler et al., 1995).

Future quantitative studies with larger samples, varied observers (self, peer, supervisor), control groups, control variables (e.g., length and timing of observation after trauma, nature of trauma), other sources of leadership effectiveness data (e.g., unit performance), and the transactional leadership styles are recommended. Studies with active duty or veteran military personnel outside the United States are also needed. Monitoring changes in the TLS through longitudinal studies is also suggested as reductions in the TLS may be temporary. Further qualitative data could be collected to gain more rich detail about changes and pre- and post- 
trauma experiences using in-depth interviews. Studies on the impact of other types of adversity in non-military samples could also be used to observe the impact of trauma or trauma-like events on the TLS.

\section{Practical Implications and Conclusion}

The ability to lead is related to the emotional, cognitive, and physical wellbeing of the leader. Trauma, whether witnessed or resulting in personal injury, has the potential to alter leaders' wellbeing and change their outward leadership behaviors. This study provides initial support for the notion that the TLS may decline after trauma, but the timing and persistence of this change needs further investigation. Previous authors, such as Bennis and Thomas (2007) and Yip and Wilson (2010), have pointed to the role of trauma and adversity in leadership development, which may result in positive or negative changes in leadership. However, literature on trauma (e.g., Matthews, 2014) would support the hypothesis that declines in the TLS following trauma exposure could be temporary for many leaders, followed by recovery and even improvement in the TLS in the longer term. Previous researchers (Wolf Williams \& Allen, 2015) have identified patterns of posttraumatic growth in leaders after trauma.

Supporting trauma-exposed military personnel remains a consistent priority, both in terms of effective training pre-trauma (e.g., resilience) and post-trauma support (e.g., counseling). In cases where trauma has a lasting impact on leaders, such leaders may require additional assistance while deployed, redeployed, or in non-military leadership roles, as PTSS or PTSD may impair their leadership, although there is evidence that effective leadership can continue while experiencing PTSS (Wolf Williams \& Allen, 2015). The negative stigma of acknowledging PTSS or PTSD (Schneider, 2012) may be an impediment to leaders recovering from trauma experiences and enacting effective leadership.

The present study's results point to a general downturn in the TLS after trauma, but these results are limited by the exploratory and cross-sectional nature of the study. If such results are confirmed by other studies, it will be appropriate to pursue organizational development interventions including programmatic support for those in active leadership roles, identifying opportunities for sabbatical placements during recovery, and monitoring for leadership performance that could suggest leadership failure. Leaders and leaders-of-leaders may also benefit from awareness of the complex nature of effects of trauma exposure, which may be associated with temporary and longer-term changes in leadership effectiveness in a negative or positive direction. 


\section{References}

Allen, S.A., \& Ortlepp, K. (2000). An investigation of the relationship between job-induced posttraumatic stress, work-based social support and three organizational variables. South African Journal of Industrial Psychology, 26(1), 1-5.

American Psychiatric Association (2013). Diagnostic and Statistical Manual of Mental Disorders (5th ed.). Washington, DC: Author.

Army, U. S. (1999). Military leadership: Be, know, do (FM 22-100). Washington, DC: U.S. Government Printing Office.

Avolio, B. J., \& Bass, B. M. (1991). The full range leadership development programs: Basic and advanced manuals. Binghamton, NY: Bass, Avolio \& Associates.

Avolio, B. J., Bass, B. M., Walumbwa, F.O., \& Zhu, W. (2004). Multifactor Leadership Questionnaire: Manual and sampler test. Redwood City, CA: Mind Garden.

Bass, B. M. (1985). Leadership and performance beyond expectations. New York, NY: The Free Press.

Bennis, W. G., \& Thomas, R. J. (2007). Leading for a lifetime: How defining moments shape the leaders of today and tomorrow. Boston, MA: Harvard Business School Press.

Bordens, K. S., \& Abbott, B. B. (2002). Research design and methods: A process approach (5th ed.). Boston, MA: McGraw-Hill.

Bossarte, R., Claassen, C. A., \& Knox, K. (2010). Veteran suicide prevention: Emerging priorities and opportunities for intervention. Military Medicine, 175(7), 461-462.

Boxer, P. A., \& Wild, D. (1993). Psychological distress and alcohol use among fire fighters. Scandinavian Journal of Work, Environment, and Health, 19(2), 121-125.

Bryman, A. (2012). Social research methods (4th ed.). New York, NY: Oxford University Press.

Burriss, L., Ayers, E., Ginsberg, J., \& Powell, D. A. (2008). Learning and memory impairment in PTSD: relationship to depression. Depression \& Anxiety, 25(2), 149-157. doi:10.1002/da.20291

Card-Mina, M. E. (2011). Leadership and posttraumatic stress symptoms. Military Review, 1(1), 47-53.

Daniel, J. (2012). Sampling essentials: Practical guidelines for making sampling choices. Thousand Oaks, CA: Sage. 
Den Hartog, D. N., Van Muijen, J. J., \& Koopman, P. L. (1997). Transactional versus transformational leadership: An analysis of the MLQ. Journal of Occupational and Organizational Psychology, 70, 19-34.

Department of the Air Force (2015), Professional Development Guide (AFHANDBOOK1), Retrieved from http://www.e-publishing.af.mil/.

Dotlich, D. L., Noel, J. L., \& Walker, N. (2004). Leadership passages: The personal and professional transitions that make or break a leader. San Francisco, CA: John Wiley \& Sons, Inc.

Gay, L. R., Mills, G. E., \& Airasian, P. W. (2006). Educational research: Competencies for analysis and applications (10 ${ }^{\text {th }}$ ed.). Upper Saddle River, NJ: Pearson Merrill Prentice Hall.

George, J. M. (2000). Emotions and leadership: The role of emotional intelligence. Human Relations, 53(8), 1027-1055.

Gunia, B. C., Sipos, M. L., LoPresti, M., \& Adler, A. B. (2015). Sleep leadership in high-risk occupations: An investigation of soldiers on peacekeeping and combat missions. Military Psychology, 27(4), 197-211. doi:10.1037/mil0000078

Fisher, K., Hutchings, K., \& Sarros, J. C. (2010). The 'bright' and 'shadow' aspects of in extremis leadership. Military Psychology, 22(Suppl 1), S89-S116. doi:10.1080/08995601003644346

Hannum, K., \& Martineau, J. W. (2008). Evaluating the impact of leadership development. San Francisco, CA: John Wiley \& Sons.

Howell, P. M. (2006). Once more into the breach: Effective leadership, coping skills, and selfefficacy as mediators between traumatic experiences and the development of PTSD in firefighters (Doctoral dissertation). Available from ProQuest Dissertations and Theses database. (UMI No. 3250579)

Howell, D. C. (2013). Statistical methods for psychology $\left(8^{\text {th }}\right.$ ed.). Belmont, CA: Wadsworth.

Ingram, J., \& Cangemi, J. (2012). Emotions, emotional intelligence and leadership: A brief, pragmatic perspective. Education, 132(4), 771-778.

Jakupcak, M., Hoerster, K. D. Varra, A., Vannoy, S., Felker, B., \& Hunt, S. (2011). Hopelessness and suicidal ideation in Iraq and Afghanistan war veterans reporting subthreshold and threshold posttraumatic stress disorder. The Journal of Nervous and Mental Disease, 199(4), 272-275. doi: 10.1097/NMD.0b013e3182124604 
Jones, N., Seddon, R., Fear, N. T., McAllister, P., Wessely, S., \& Greenberg, N. (2012). Leadership, cohesion, morale, and the mental health of UK armed forces in Afghanistan. Psychiatry, 75(1), 49-59.

Judge, T. A., \& Piccolo, R. F. (2004). Transformational and transactional leadership: A metaanalytic test of their relative validity. Journal of Applied Psychology, 89(5), 755-768. doi:1037/0021-9010.89.5.755

Kets de Vries, M. F. (2006). The leadership mystique: Leading behavior in the human enterprise $\left(2^{\text {nd }}\right.$ ed.). Harlow, England: Prentice Hall Financial Times.

Kessler, R. C., Sonnega, A., Bromet, E., Hughes, M., \& Nelson, C. B. (1995). Posttraumatic stress disorder in the National Comorbidity Survey. Archives of General Psychiatry, 52(12), 1048-1060.

Kolditz, T. A. (2007). In extremis leadership: Leading as if your life depended on it. San Francisco, CA: John Wiley \& Sons.

Kolditz, T. (2009, February 6). Why the military produces great leaders. Harvard Business Review. Retrieved from: https://hbr.org/2009/02/why-the-military-produces-grea

Krathwohl, D. R. (2009). Methods of educational and social science research: The logic of methods ( $3^{\text {rd }}$ ed.). Long Grove, IL: Waveland Press.

Matthews, M. D. (2013). Head strong: How psychology is revolutionizing war. New York, NY: Oxford University Press.

McCall, M. W, Lombardo, M. M, \& Morrison, A. M. (1988). The lessons of experience: How successful executives develop on the job. New York, NY: Lexington Books.

Moxley, R. S., \& Pulley, M. L. (2004). Hardships. In C. D. McCauley \& E. Van Velsor (Eds.), Handbook of leadership development (2 ${ }^{\text {nd }}$ ed., pp. 183-203). San Francisco, CA: JosseyBass.

Nunnally, J. C. (1967). Psychometric theory (1st ed.). New York, NY: McGraw-Hill.

O'Connor, M., Lasgaard, M., Spindler, H., \& Elklit, A. (2007). The impact of different diagnostic criteria on PTSD prevalence: A comparison of PTSD prevalence using the DSM-IV and ICD-10 PTSD-criteria on a population of 242 Danish social work students. Nordic Psychology, 59(4), 317-331. doi:10.1027/1901-2276.59.4.317

Patton, M. Q. (2014). Qualitative research and evaluation methods: Integrating theory and practice. Thousand Oaks, CA: Sage. 
Peterson, S. J., Walumbwa, F. O., Byron, K., \& Myrowitz, J. (2009). CEO positive psychological traits, transformational leadership, and firm performance in high-technology start-up and established firms. Journal of Management, 35(2), 348-368. doi:

$10.1177 / 0149206307312512$

Podsakoff, P. M., MacKenzie, S. B., Lee, J. Y., \& Podsakoff, N. P. (2003). Common method biases in behavioral research: a critical review of the literature and recommended remedies. Journal of Applied Psychology, 88(5), 879-903.

Pratt, C. C., McGuigan, W. M., \& Katzev, A. R. (2000). Measuring program outcomes: Using retrospective pretest methodology. American Journal of Evaluation, 21(3), 341.

Schneider, J. J. (2012). A leader's grief: T.E. Lawrence, leadership, and PTSD. Military Review, 92(1), 75-80.

Tejeda, M. J., Scandura, T. A., \& Pillai, R. (2001). The MLQ revisited: Psychometric properties and recommendations. The Leadership Quarterly, 12(1), 31-52.

Tedeschi, R., \& Calhoun, L. G. (2004). Posttraumatic growth: Conceptual foundations and empirical evidence. Psychological Inquiry, 15(1), 1-18.

Thomas, R. J. (2008). Crucibles of leadership: How to learn from experience to become a great leader. Boston, MA: Harvard Business Press.

Thompson, H. L. (2010). The stress effect: Why smart leaders make dumb decisions. San Francisco CA: Jossey-Bass.

Wood, M. D., Foran, H. M., Britt, T. W., \& Wright, K. M. (2012). The impact of benefit finding and leadership on combat-related PTSD symptoms. Military Psychology, 24(6), 529-541. doi: 10.1080/08995605.2012.736321

Wolf Williams, J., \& Allen. S. (2015). Trauma-inspired prosocial leadership development. Journal of Leadership Education, 14(3), 86-103.

Yip, J., \& Wilson, M. S. (2010). Learning from experience. In E. Van Velsor, C. D. McCauley, \& Ruderman, M. N. (Eds.), Handbook of leadership development ( $3^{\text {rd }}$ ed., pp. 63 - 95). San Francisco, CA: Jossey-Bass.

Zineldin, M., \& Hytter, A. (2012). Leaders' negative emotions and leadership styles influencing subordinates' well-being. International Journal of Human Resource Management, 23(3), 748-758. doi:10.1080/09585192.2011.606114 


\section{Author Biographies}

Charles Kramer (ckramer@ vinu.edu) is an adjunct professor for Vincennes University extension Campus in San Diego CA. He is retired from US Navy and currently is the director for Professional Education for the Naval Medical Center San Diego. He develops programs to develop both military and civilian personnel leadership competencies.

Dr. Stuart Allen (allens@ rmu.edu) is an associate professor in the organizational leadership department at Robert Morris University and a dissertation chair for Ed.D. Organizational Leadership and D.Sc. Information Systems and Communication programs. He conducts research on leadership education, pedagogy, leadership, posttraumatic stress disorder, organizational behavior, and teaching with technology. 